\title{
Automated sugar analysis
}

\author{
Tadeu Alcides MARQUES ${ }^{1 \star}$, Érick Malheiros RAMPAZO ${ }^{1}$, Rafael Rebes ZILLIANI ${ }^{1}$, \\ Patricia Angélica Alves MARQUES ${ }^{2}$, Fabio BENINCASA ${ }^{1}$
}

\begin{abstract}
Sugarcane monosaccharides are reducing sugars, and classical analytical methodologies (Lane-Eynon, Benedict, complexometricEDTA, Luff-Schoorl, Musson-Walker, Somogyi-Nelson) are based on reducing copper ions in alkaline solutions. In Brazil, certain factories use Lane-Eynon, others use the equipment referred to as "REDUTEC", and additional factories analyze reducing sugars based on a mathematic model. The objective of this paper is to understand the relationship between variations in millivolts, mass and tenors of reducing sugars during the analysis process. Another objective is to generate an automatic model for this process. The work herein uses the equipment referred to as "REDUTEC", a digital balance, a peristaltic pump, a digital camcorder, math programs and graphics programs. We conclude that the millivolts, mass and tenors of reducing sugars exhibit a good mathematical correlation, and the mathematical model generated was benchmarked to low-concentration reducing sugars $(<0.3 \%)$. Using the model created herein, reducing sugars analyses can be automated using the new equipment.
\end{abstract}

Keywords: mathematical modeling; monosaccharide; chemical determination.

Practical Application: This work can be used to develop technological innovations in reducing sugars food analysis procedures using mathematical modeling and computational sensor snapshots.

\section{Introduction}

To ensure increased sugar production, ethanol and bioelectricity are necessary expansions for sugarcane plantations (Companhia Nacional de Abastecimento, 2012), and productivity increases with better quality raw materials (Michelazzo \& Braunbeck, 2008). In Brazil, sugarcane quality is routinely monitored using technological analyses of Pol (\% of apparent sucrose), Brix (\% soluble solids), RS (\% reducing sugars), and fiber; the TRS (total reducing sugars) and ATR (total recoverable sugars) are also calculated (Fernandes, 2000). Industrial units use different methodologies and analytical protocols that are recognized and approved by the ICUMSA (International Commission for Uniform Methods of Sugar Analysis) and INMETRO-BRASIL (National Institute of Metrology, Quality and Technology). The monosaccharides (glucose and fructose) in sugarcane are reducing sugars (RS) with a free carbonyl group that can oxidize in the presence of oxidizing agents (Mattos, 1991). The classical methods include Lane \& Eynon, de Benedict, complexometric-EDTA, Luff-Schoorl, Musson-Walker, and Somogyi-Nelson and are based on copper ion reduction in alkaline solutions (McClements, 2014; Silva et al., 2003). Certain factories use titration hot (Lane \& Eynon, 1934), others mathematically calculate the RS, and others use the apparatus referred to as REDUTEC, which determines reducing sugars as proposed by Horii and Gonçalves (Horii \& Gonçalves, 1991). These procedures should be standardized for increased reliability of the results and better comparisons between levels of efficiency among different industrial units.
According Isejima et al. (2002), even after adjustments using the REDUTEC, the RS (reducing sugars) methodology cannot meet demands of industries, which receive many samples from different stands of cane. The RS is also analyzed in materials for industrial processes at different stages of manufacturing, such as reception, milling suit, and manufacturing sugar, totaling approximately 800 tests per day.

We inserted a platinum electrode into the REDUTEC device. These procedures were used to aid in determining the turning point reaction, which, until then, could only be visually evaluated for a color change. We observed that, during the titration, the change in millivolts generated in copper Fehling's reaction with reducing sugars decreases gradually and, when it reaches the turning point values, the $\mathrm{mV}$ exhibited a large variation referred to as "shooting".

The hypothesis of this work is that a mathematical model can correlate the concentration of reducing sugars (in a sample) with variation in the oxidation-reduction potential of Fehling's solution (measured in $\mathrm{mV}$ ) and variation in the mass of a sugar solution that is spent during the titration process (measured in $\mathrm{g}$ ). This model can mathematically estimate the quantity of reducing sugars in a sample using the kinetics of variation for the oxidation-reduction potential and kinetics of the mass change during titration. In this case, we can automate the quantitation of reducing sugars (RS) using the REDUTEC device, an electronic record of the mass (based on an automatic scale using the RS 232 output) and the redox potential of the record (using an electronic

${ }^{1}$ Centro de Estudos Avançados em Bioenergia e Tecnologia Sucroalcooleira - CENTEC, Universidade do Oeste Paulista - UNOESTE, Campus II, Presidente Prudente, SP, Brasil

${ }^{2}$ Departamento de Engenharia de Biossistemas, Instituto Nacional de Ciência e Tecnologia: Engenharia da Irrigação - INCT-EI, Escola Superior de Agricultura "Luiz de Queiroz" - ESALQ, Universidade de São Paulo - USP, Piracicaba, SP, Brasil

*Corresponding author: tmarques@unoeste.br; tmarques@uol.com.br 
potentiometer with the RS 232 output) without depending on color change or relying on human eye acuity. Our goal was to create a mathematical model in a tangible format to evaluate the change in millivolts, mass and concentration of reducing sugars (RS) using a duly adapted REDUTEC device. Moreover, after creating the model, we performed experiments using sugarcane natural broths, adjusted the model to generate a real, definite and predictable model and propose creation of new automated equipment as well as a new means of quantitating reducing sugars (RS).

\section{Materials and methods}

The model's mental formulation (hypothesis)

The oxi-reduction reaction between copper $(\mathrm{Cu})$ and reducing substances (RS) promotes a color change from blue to colorless when the $\mathrm{Cu}^{+2}$ (cupric) cations are reduced to $\mathrm{Cu}^{+1}$ (cuprous). In solution, iron ( $\mathrm{Fe})$ is oxidized, which accentuates a red color. At the turning point for the colors, using titrimetric determinations, one can measure the concentration of reducing substances using the following model (Equation 1):

$$
R S=\frac{T}{V u x d} \text { ou } R S=\frac{T}{M u}
$$

wherein:

$$
\begin{aligned}
& \mathrm{RS}=\text { reducing substances }(\%) ; \\
& \mathrm{Vu}=\text { volume of sugar solution used in the titration process }
\end{aligned}
$$
$(\mathrm{mL})$;

$$
\mathrm{d}=\text { solution density relative to water }\left(\mathrm{g} \mathrm{mL}^{-1}\right) \text {; }
$$

$\mathrm{Mu}=$ mass of the sugar solution used in the titration process (g); and

$\mathrm{T}=$ title (mass of glucose that reacts with $1 \mathrm{ml}$ of liquor multiplied by 1000; this value is typically close to 5 ).

When the model was used to determine the values of the reducing substances, a similar variation provided lower differences in concentration where the mass values were high (Figure 1).

The copper solution redox $(\mathrm{mV})$ value can be considered constant at the beginning of the titration process, and this value changes by adding reducing substances, which reduce copper $(\mathrm{Cu})$ and induce small changes in the redox value at the beginning of the process. As the changes due to the titration increase, copper is increasingly reduced (Figure 2).

This assumption is justified by the practical curves, in which the same mass variation provides the greatest difference in oxidation-reduction with greater mass values (Figure 3 ), which yields the following general function (Equation 2):

$\mathrm{mV}=\mathrm{F}+\mathrm{G} * \mathrm{mg}+\mathrm{H} * m g^{2}+\mathrm{I} * m g^{3}+\mathrm{J} * m g^{4}$

wherein:

$\mathrm{mV}=$ redox potential in millivolts, and

F, G, H, I and J = values that depend on the sugar concentration of the solution.
We obtained the following based on the experiments:

$\mathrm{F}=232.19$ to 232.77 ;

$\mathrm{G}=-20.68$ to -8.13 ;

$\mathrm{H}=4.40$ to 7.35 ;

$\mathrm{I}=-1.00$ to -0.68 ;

$\mathrm{J}=0.046$ to 0.060 ; and

$\mathrm{mg}=$ mass of the sugar solution used in the titration process.

In studying the effects of both together (redox potential and mass), we can observe the intersection of the curves, which occurs at different points and can express the values of the reducing substances in the sample (Equation 3).

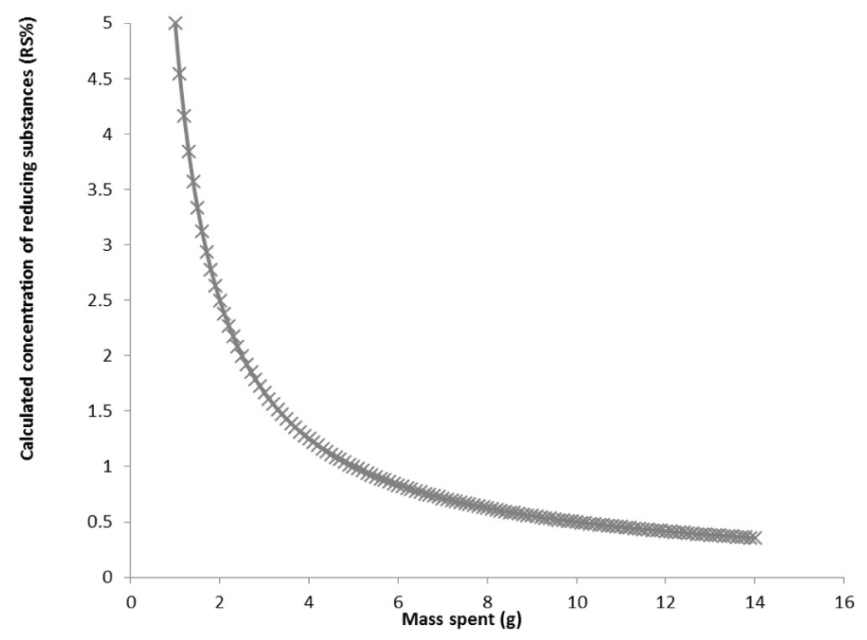

Figure 1. Hypothetical values of reducing substances calculated using the model from Equation 1.

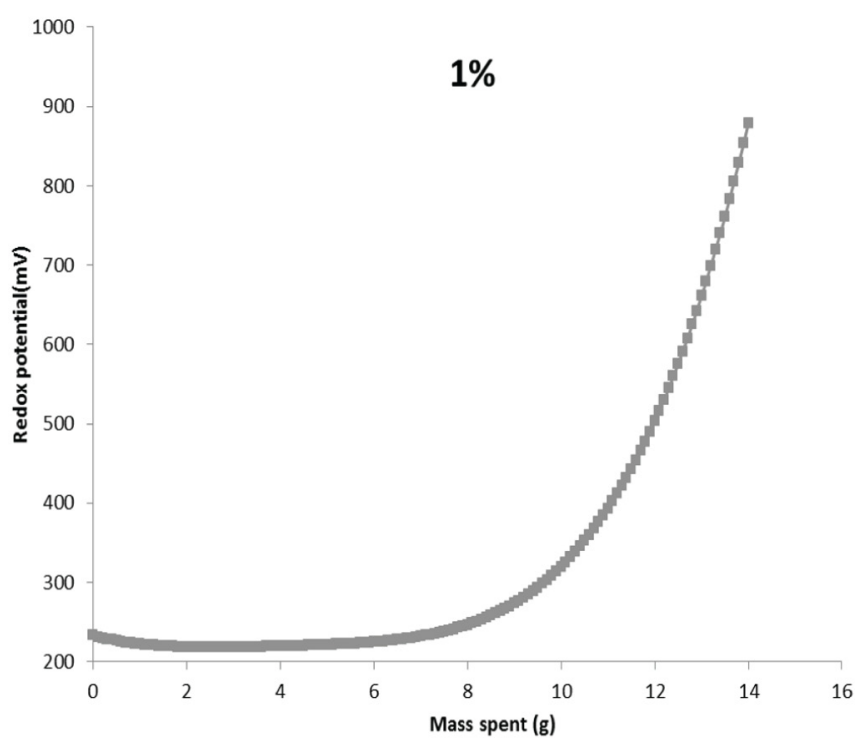

Figure 2. Redox values during the titration process for a $1 \%$ reducing sugars (RS) solution. 

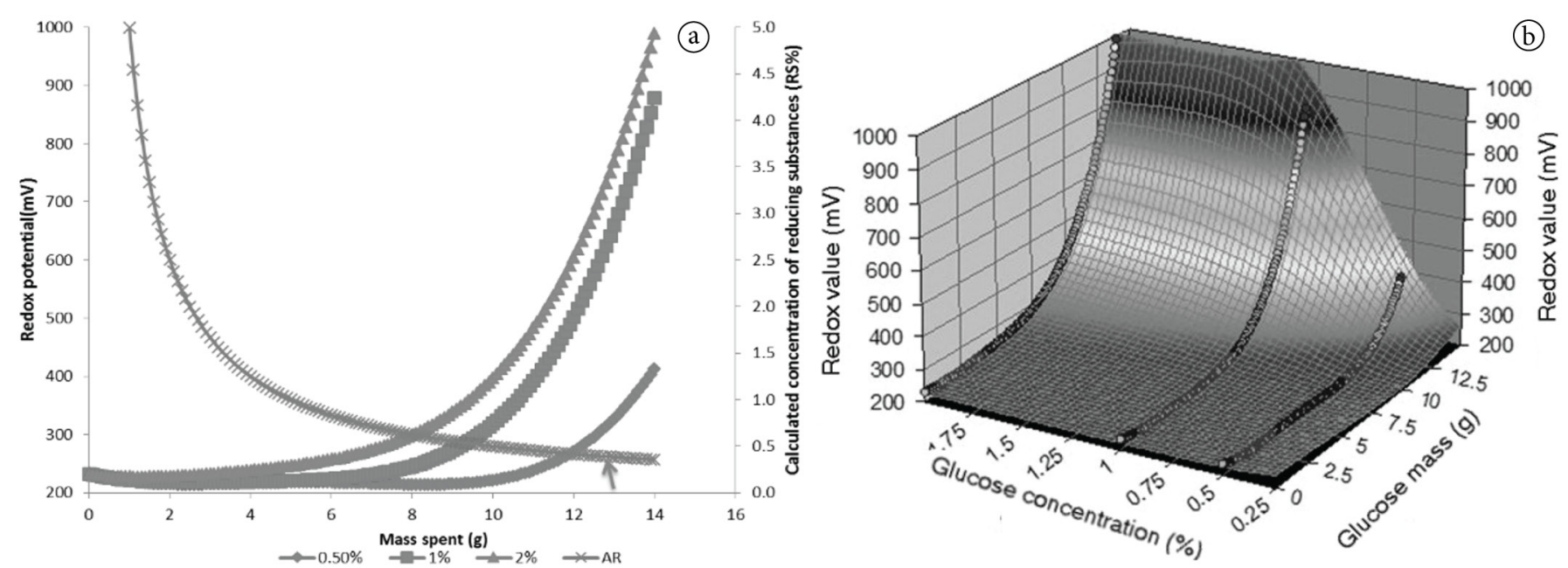

Figure 3. (a) Polynomial curves obtained in Microcal Origin 6.0 software to concentrations of $0.5 \%, 1.0 \%$ and $2.0 \%$. (b) Surface three-dimensional obtained in "Table Curve 3D" mathematical program, after modeling the "Maple 13" program and obtaining model, Concentration $\%=\mathrm{f}(\mathrm{mV}$, mass spends).

$R S=\frac{T+(F-m V) * m g+G^{*} m g^{2}+H^{*} m g^{3}+I^{*} m g^{4}+J^{*} m g^{5}}{m g}$

wherein:

$\mathrm{RS}=$ reducing substances;

$\mathrm{T}=$ title (mass of glucose that reacts with $1 \mathrm{ml}$ liquor) multiplied by 1000 , which produces a value that is typically close to 5 (Caldas, 2005);

$\mathrm{mg}=$ mass of the sugar solution used in the titration process (g); and

F, G, H, I and J = variables that depend on the sugar concentration in the solution.

The mathematical model (Equation 3) allows one to calculate the reducing substances (sugars) content based on the mass used and redox potential, wherein the inflection point of the curve (Figure 4) expresses the value of the sugar concentration in the solution.

The experiment was performed using the following three (3) steps.

STEP 1: Using glucose, fructose and mixed solutions (glucose and fructose in equal parts) at the concentrations $0.5 \% ; 1.0 \%$ and $2.0 \%$, we calibrated the metering pump and adjusted it to obtain the best flow titration.

The cane sugar broth contains glucose and fructose as reducing sugar components with proportions that depend on many factors, such as the sugarcane cultivar, cultivation, plant age, and maturity stage. If the glucose and fructose composition interferes with the analytical process, one must understand the mechanisms of interference for a more accurate analysis.

The dispersion of the points (redox values) in the graphics were evaluated $(\mathrm{mV})$ compared with the mass used $(\mathrm{g})$ to reach the "turning" point. The values were obtained using the REDUTEC Model TE-088, the digital balance MARK M4102, the peristaltic pump model TE-BP-01 and connections (Tecnal

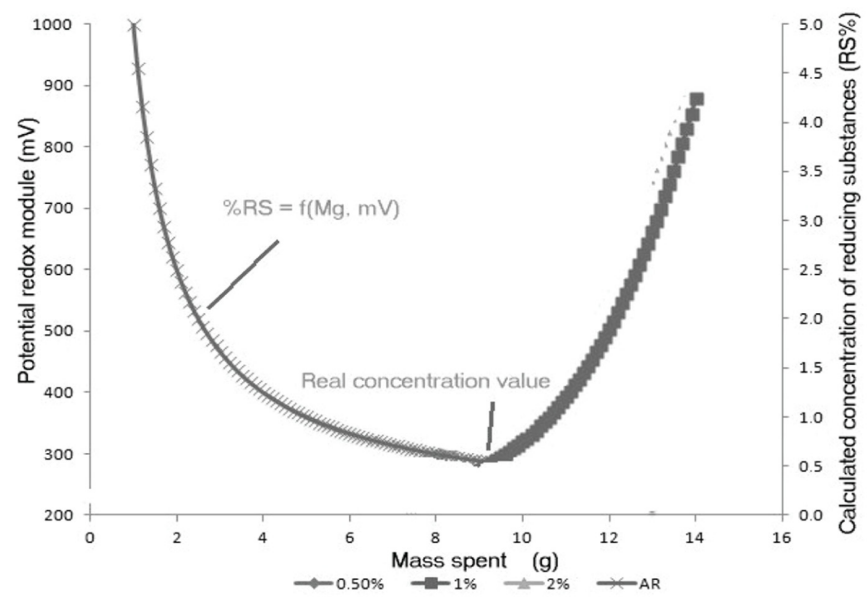

Figure 4. The mathematical model with an inflection point for determining the reducing sugars.

Equipamentos Científicos, 2015). For each analysis, the redox values $(\mathrm{mV})$ and mass spent $(\mathrm{g})$ were indicated as the blue color changes to red.

STEP 2: We used the mixed solutions with glucose and fructose concentrations at $0.5 \% ; 1.0 \%$ to $2.0 \%$ from step 1 . The analyses were monitored every 5 seconds, we recorded the weight, and we used millivolt values. For more accurate values during the titration process, we used the camcorder SONY CYBER-SHOT SUPER STEADYSHOT 5.1 MEGAPIXELS, which recorded images during titration; we used specific software (MS Windows media player) to collect the mass and millivolts; and we correlated the different concentrations using MicroCal Origin 6.0.

We used the models generated and the program "Table Curve 3D" for response surface mounting to develop the three-dimensional model (concentration, millivolt and mass). We later used the numerical method Newton-Raphson to solve equations with implicit variables and the mathematical software 
Maple 14 to isolate the variable concentration mass function and millivolts used.

STEP 3: The three-dimensional model was validated using different, standardized sugarcane broths $(0.3 \%, 0.2 \%$ and $0.1 \%$ RS).

\section{Results and discussion}

The results and discussion are presented based on the experimental steps.

\subsection{Step 1}

For better performance and perfect functionality, in simulating traditional titrametric analyses, the flow of work should be $0.37 \mathrm{~g} \mathrm{~s}^{-1}$.
After testing and determining the initial settings, we performed titrations of glucose, fructose and mixed solutions at $0.5 \%, 1.0 \%$ and $2.0 \%$ concentrations. The minor variations were combined, VC redox was multiplied $(\mathrm{mV}$ ), and the mass of the $\mathrm{VC}$ (variation coefficient) spent (g) in the mixed solution exhibited lower values at the lower reducing substances concentrations. This smaller VC demonstrates that mixed solutions yield greater analytical precision, which facilitates the continued search for a mathematical model design for reducing sugar solutions with glucose and fructose in varying proportions. For processing, sugarcane must have a good maturation state, which indicates low tenor reducing sugars that are typically minor at $0.5 \%$, which is also positive according to the results from Step 1 (Figure 5).
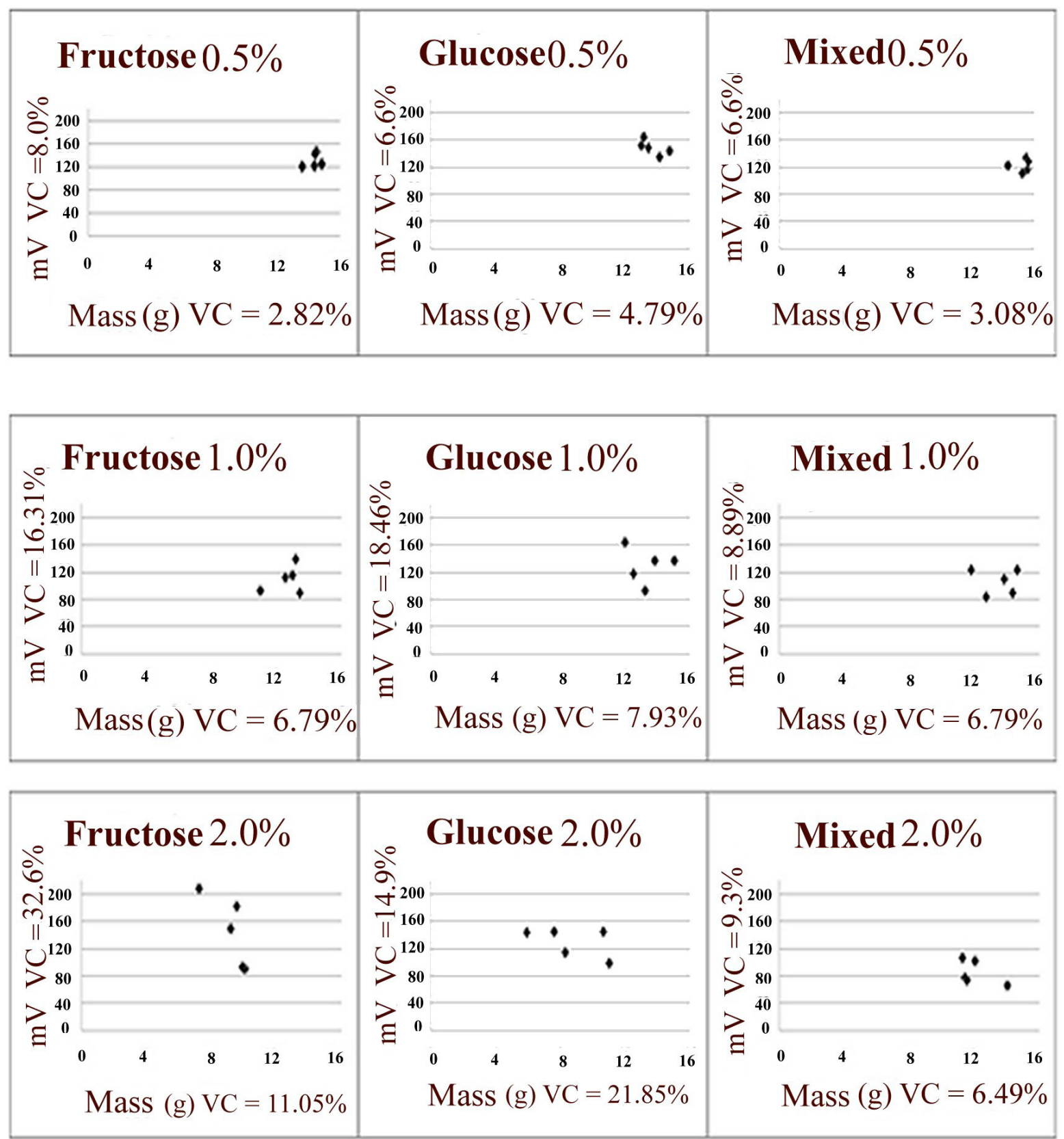

Figure 5. The results for VC mass and VC millivolt at the time of color turning using the concentrations $0.5 \%$; $1.0 \%$ and $2.0 \%$ for fructose, glucose and the mixed solution (50\% each). 
The greatest variation in the pure glucose and fructose solutions was due to different kinetics between the copper reaction with the reducing sugar (pyran and furans); both exhibit a two-way reaction with different speeds. The redox potential in a pure solution will oscillate with high intensity by exhibiting an increase in change as the sugar concentration increases. Simultaneous reactions occur with the sugar mixture, which adds to the effect of the titrimetric analysis time and chemical reaction time, produces more stable redox values and is less prone to erroneous readings. When glucose and fructose solution mixtures are used, lower concentrations also yield more accurate values.

\subsection{Step 2}

The polynomial regressions and $\mathrm{R} 2$ values with a $1 \%$ significance are shown in Figure 2, which statistically illustrates the mathematical model for mass spent during titration and the millivolts of the copper solution. The models are mathematically similar, but the coefficients differ for different concentrations with a mathematical trend.

The coefficient intervals are: $\mathrm{F}=232.19$ to 234.47 ; $\mathrm{G}=-20.68$ to $-8.13 ; \mathrm{H}=4.40$ to $7.35 ; \mathrm{I}=-1.00$ to -0.68 ; and $\mathrm{J}=0.046$ to 0.060 (Figure $3 \mathrm{~b}$ ).

The three mathematical models show that the slope of the curves are proportional to the sugar concentration, and the inflection point occurs at the color shift for the different concentrations tested (Figure 3 ). Thus, the curves and sugar concentrations are related. Based on this relationship, the surface response was modeled as follows:

$\mathrm{mV}=\mathrm{f}($ conc.$\%$, mass $)$ (Figure $3 \mathrm{~b})$.

After applying the numerical method to isolate the variable concentration of the three-dimensional model, the following model was generated for Concentration $(\%)=\mathrm{f}(\mathrm{mV}, \mathrm{mg})$ (Equation 4).

Concentration $(\%)=e^{-\left[\frac{1}{A}(0,025(B+\sqrt{(C+D)}))\right]}$

wherein:

$$
\begin{aligned}
& \mathrm{A}=-1.11^{\star} 1010+3.02 * 107^{\star} \mathrm{mV} \text {; } \\
& \mathrm{B}=1.22{ }^{\star} 109{ }^{\star} \mathrm{mV}-2.90{ }^{\star} 1011-1.14^{\star} 108^{\star} \mathrm{mg}-9.00 \\
& \text { * } 107{ }^{*} \mathrm{mV}{ }^{\star} \mathrm{mg} \text {; } \\
& \mathrm{C}=-2.27^{\star} 1019^{\star} \mathrm{mV}^{2}+1.35^{\star} 1022^{\star} \mathrm{mV}-1.90^{\star} 1021^{\star} \mathrm{mV} \\
& { }^{\star} \mathrm{mg}+3.04{ }^{\star} 1018^{\star} \mathrm{mV}^{2 \star} \mathrm{mg}-1.89{ }^{\star} 1024+2.77^{\star} 1023^{\star} \mathrm{mg} \text {; and } \\
& \mathrm{D}=-1.15^{*} 1022 \text { * } \mathrm{mg}^{2}+7.36 \text { * } 1019 \text { * } \mathrm{mV} \text { * } \mathrm{mg}^{2}-1.07 \text { * }
\end{aligned}
$$

\subsection{Step 3}

The sugarcane broths were analyzed by the model developed herein with the mass spent and millivolt measurements every 5 seconds during the titration process. The RS values were calculated based on the mathematical model (Equation 4), and the results are presented in Table 1.

Table 1. The RS values calculated using the mathematical model Conc $\%=f(m V$, mass $)$ during the titration process. Three different concentrations of broth were used.

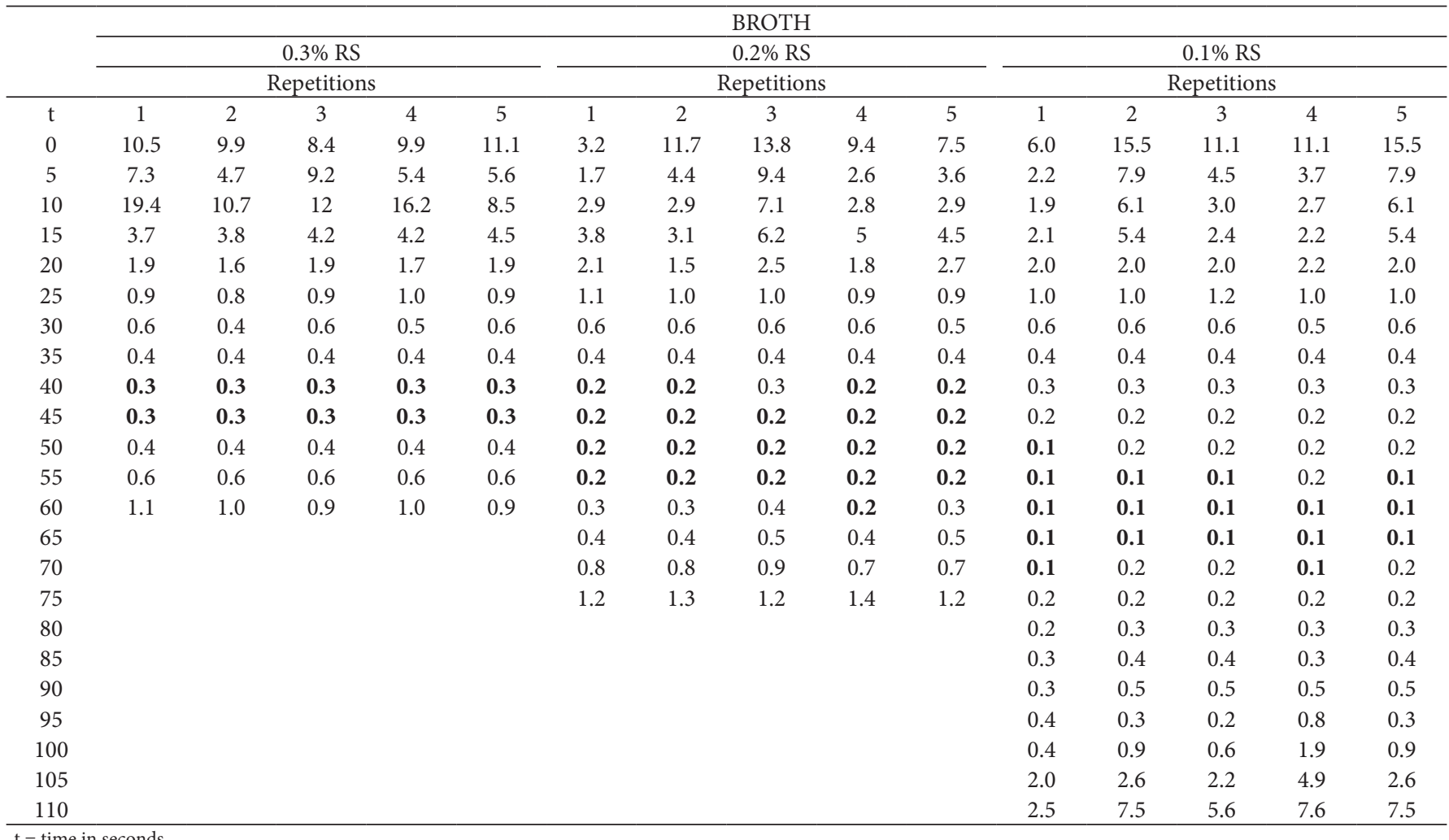


The calculated values decrease until they reach a minimum value that coincides with the concentration generated using the traditional method. The millivolt values $(\mathrm{mV})$ and mass (mg) can be provided to a computer, and the computation are performed instantaneously to determine the concentration value without using color or any other attribute based on the following algorithm logic:

$$
\begin{aligned}
& \text { Time }=0 \\
& \text { Result }=0 \\
& \text { RS current }=0 \\
& \text { RS previous }=100000 \\
& \text { While Result }=0 \text { do }
\end{aligned}
$$

Get $\mathrm{mV}$ (obtaining the signals of the electrode and conversion into value, always positive (module))

Fet $\mathrm{mg}$ (obtaining the signals of balance and conversion to $\mathrm{mg}$ )

RS current $=\mathrm{f}(\mathrm{mV} \cdot \mathrm{mg})$ (the calculations) (Equation 4)

If(1) the value of RS current $<=5$

$$
\text { if(2) RS current - RS previous }>0
$$

$$
\text { Result }=\text { RS previous }
$$

End if(2)

Else if $(1)$

Do

RS previous $=$ RS current

Time $=$ Time +1

End

End if(1)

Back in while.

\section{Conclusions}

A mathematical model was generated to correlate millivolts, mass and RS. The mathematical model generated exhibited positive measurements for low-concentration RS solutions $(<0.3 \%)$. This model can be used for automation and to reduce analysis time.

\section{Acknowledgements}

For CENTEC due to the support given to research.

\section{References}

Caldas, C. (2005). Teoria básicas de análises sucroalcooleiras. Maceió: Central Analítica.

Companhia Nacional de Abastecimento - CONAB. (2012). Acompanhamento de safra brasileira: cana-de-açúcar, segundo levantamento. Brasília: CONAB. Retrieved from: http://www.conab.gov.br/OlalaCMS/ uploads/arquivos/12_08_09_15_07_05_boletim_cana_portugues_-agosto_2012_2o_lev.pdf

Fernandes, A. C. (2000). Cálculos na Agroindústria da cana de açúcar. Piracicaba: STAB Açúcar, Álcool e Subprodutos.

Horii, J., \& Gonçalves, R. H. (1991). Um método alternativo para a determinação de AR e ART. STAB Açúcar, Álcool e Subprodutos, $10,45-47$.

Isejima, E. M., Costa, J. A. B., \& Souza, D. I. Jr. (2002). Método de determinação de açúcares redutores aplicável no sistema de pagamento de cana-de-açúcar. Pesquisa Agropecuaria Brasileira, 37(5), 729-734. http://dx.doi.org/10.1590/S0100-204X2002000500020.

Lane, J. H., \& Eynon, L. (1934). Determination of reducing sugars by Fehling's solution with methylene blue indicator. London: Normam Rodge.

Mattos, I. L. (1991). Determinação sequencial de frutose e glicose em materiais de relevância agro-industrial utilizando sistemas de análise por injeção em fluxo (Dissertação de mestrado). Centro de Energia Nuclear na Agricultura, Universidade de São Paulo, Piracicaba.

McClements, J. (2014). Analysis of food products. Massachusetts: University of Massachusetts Amherst, UMass Amherst Information Technology. Retrieved from http://people.umass.edu/ mcclemen/ 581Carbohydrates.html

Michelazzo, M. B., \& Braunbeck, O. A. (2008). Análise de seis sistemas de recolhimento do palhiço na colheita mecânica da cana-de-açúcar. Revista Brasileira de Engenharia Agrícola e Ambiental, 12(5), 546-556. http://dx.doi.org/10.1590/S1415-43662008000500017.

Silva, L. F. L. F., Bernardino, C. D., Ré, F. E., Furtado, C. H. F., \& Amorim, H. V. (2003). Métodos analíticos para o controle da produção de açúcar e álcool. Piracicaba: Fermentec.

Tecnal Equipamentos Científicos - TECNAL. (2015). Produtos por segmento. Piracicaba: TECNAL. Retrieved from: http://www.tecnallab. com.br/default.aspx?rnd $=454366974$ 